\title{
Outcome of GnRH antagonist ICSI cycles triggered by GnRH agonist plus Recombinant hCG versus triggered with Recombinant hCG alone in fresh autologous ICSI cycle
}

Received: 09-Oct-2020 Accepted: 17-Nov-2020 Published: 21-Dec-2020

Wafaa Mohammed Abed*, Mohammed Oda Selman

High Institute of Infertility Diagnosis and Assisted Reproductive Technologies, Al Nahrain University, Baghdad, Iraq. *dwafam.wasit@gmail.com

To explore whether dual triggering for final oocyte maturation using a low dose of recombinant human chorionic gonadotropin (hCG) plus gonadotropinreleasing hormone agonist ( $\mathrm{GnRH}-\mathrm{a})$ is as effective as the standard dose of recombinant hCG triggering alone in term of a total number of retrieved oocytes, fertilization and pregnancy rate in fresh autologous antagonist intracytoplasmic sperm injection (ICSI) cycles. 80 infertile women undergoing ICSI, aged $<40$ years, $18<$ Body mass index $<30 \mathrm{Kg} / \mathrm{m} 2$ included in fresh autologous antagonist ICSI cycles. 40 women received a Standard dose of recombinant hCG $(500 \mu \mathrm{g})$ alone and 40 women received GnRH-a $(0.2 \mathrm{mg}$ triptorelin plus $250 \mu \mathrm{g}$ recombinant hCG) were used for final oocytes maturation. This study was conducted at the High Institute for Infertility Diagnosis and Assisted Reproductive Techniques, Al Nahrain University. The mean total number of retrieved oocytes, fertilization, and pregnancy rate were measured. The mean total oocyte number being statistically higher in the dual trigger group. The mean number of fertilized oocytes and clinical pregnancy rates was higher in the dual trigger group than in the control group, but the difference showed borderline statistical significance. Furthermore, fertilization rates show no statistical difference between the control group and the dual trigger group. Results of the study confirm that dual triggers show favorable improvement in fresh autologous antagonist ICSI cycles with the use of GnRH agonists plus hCG compared with hCG alone for triggering of final oocyte maturation.

Keywords: Dual trigger; Recombinant hCG plus GnRH agonist; Total number of retrieved oocytes. 


\section{Introduction}

The most essential part of in vitro fertilization (IVF) and intracytoplasmic sperm injection (ICSI) is to control ovarian stimulation with exogenous gonadotropin to retrieve a rational number of mature oocytes for IVF and ICSI (Allegra, et al., $\left.{ }^{[1]}\right)$. Gonadotropin-releasing hormone $(\mathrm{GnRH})$ antagonist protocol is the alternative protocol that has been used to achieve competitively block the GnRH receptors causing immediate gonadotropin suppression and prevent premature $\mathrm{LH}$ surge without suppression of early follicular development within few hours of their administration (Behery, et al., ${ }^{[2]}$ ). Induce final oocyte maturation with hormonal stimulus has a major influence on retrieval oocyte, implantation rate, and safety which is characterized by the risk of ovarian hyperstimulation syndrome (OHSS) that is the most dangerous complication associated with control ovarian stimulation in assisted reproductive techniques (ART). The surge of follicular stimulating hormone (FSH) induces LH receptor formation on luteinized granulosa cells and promotes oocytes maturation through stimulating the resumption of oocyte meiosis and cumulus expansion (Griffin, et al., ${ }^{[3]}$ ). When a GnRH agonist is given, causes an endogenous FSH and LH surge which mimic physiologically the natural cycle. Preparation of the mature follicles for the preovulatory LH surge results in granulosa cell luteinization (Lawrenz, et al., ${ }^{[4]}$ ). Although it results in shortness of $\mathrm{LH}$ surge duration, and a negative effect on endometrial receptivity with subsequent abnormal corpora lutea formation, this Shortness duration of the induced LH/FSH peak leads to deficient luteal phase with premature luteolysis and implantation failure (El Tokhy, et al., ${ }^{[5]}$ ). In dual trigger hCG supply more sustained support for the luteal phase, effectively reduce the risk of OHSS as well as result in many mature oocytes, embryo quality, implantation rate, ongoing pregnancy, and live birth rate. (Eftekhar, et al., ${ }^{[6]}$ ). The study aimed to confirm the concept of the 
dual trigger with $0.2 \mathrm{mg}$ triptorelin plus $250 \mu \mathrm{g}$ recombinant hCG for final oocyte maturation, regarding the number of the oocyte, fertilization, and pregnancy rate as effective as using standard recombinant hCG triggering alone in fresh autologous antagonist ICSI cycles.

\section{Materials and Methods}

The selected 80 infertile women undergoing ICSI, were enrolled in this prospective study from November 2018 to September 2019. This study was conducted at the high institute for infertility diagnosis and assisted reproductive techniques, Al Nahrain University, Baghdad, Iraq. The patient's inclusion criteria were $18 \mathrm{~kg} / \mathrm{m}^{2}<$ Body mass index $<30 \mathrm{~kg} / \mathrm{m}^{2}$, and age $\leq 40$ years. The exclusion criteria were endocrine disorder, congenital uterine anomalies disorder, patients with high basal FSH level $\geq 10 \mathrm{IU} / \mathrm{L}$ and low AMH hormone $\leq 1.0 \mathrm{ng} / \mathrm{ml}$ (poor ovarian reserve), recurrent implantation failure (RIF), and male infertility azoospermia (Rosini, et al. $\left.{ }^{[7]}\right)$. The selected 80 women are intentionally divided, into 40 women who undergo antagonist protocol with dual trigger and 40 women undergo antagonist protocol with recombinant human chorionic gonadotrophin (hCG) trigger. all infertile couples registered in this study undergo ultrasound examination on the second or third day of the cycle (CD2-3) to exclude ovarian cyst, estimate antral follicle count, and measure the endometrial thickness. Basal hormonal investigation performed and start ovarian stimulation with 150-225 IU of Gonal F (Merk $^{\circledR} 75$ IU FSH/ampule) by fixed daily subcutaneous administration.

Desensitization of pituitary starts according to ultrasound monitoring when leading ovarian follicles to reach 12-14 $\mathrm{mm}$ GnRH antagonist cetrorelix start $(0.25$ mg cetrotide, Merck Serono, Switzerland) in daily subcutaneous injection according to the multiple-dose regime. On a day of trigger serum estradiol level perform for each patient and ovulation trigger was done when the leading follicle reaches 17 $18 \mathrm{~mm}$ and $\mathrm{E}_{2} \geq 500 \mathrm{pg} / \mathrm{ml}$. Group 1, was 
triggered by hCG (Oviterell ${ }^{\circledR} 250 \mu \mathrm{g}$, Merck, Italy) subcutaneous injection plus $\mathrm{GnRH}$ agonist triptorelin $0.2 \mathrm{mg}$ (Decapeptil ${ }^{\circledR}$; ferric, Kiel, Germany). For group II, the ovulation trigger is done by Oviterell ${ }^{\circledR} 500 \mu \mathrm{g}$ subcutaneous injection was done. (Vuong, et al., ${ }^{[8]}$ ). 35-36 hours after ovulation triggering (hCG and dual) oocyte retrievals were done under the transvaginal ultrasound guide. Serum Estradiol, progesterone, testosterone, and $\beta$-hCG hormone level was done. ICSI was performed, confirm fertilization by the presence of two pronuclei (2PN). Embryo transfers were done on Day 2, 3, or 5 after oocyte retrievals. Luteal phase support performed through progesterone support in form of depot injection $250 \mu \mathrm{g}$ primolute depot (Hydroxyprogesreone caproate Bayer) deep intramuscular injection every three days or vaginally suppositories $400 \mathrm{mg}$ (cyclogest, Actavis Barnstaple $^{\circledR}$ ) (Mohammed, et al. ${ }^{[9]}$ ) twice daily starting on the same day of oocyte retrievals. The primary outcome was pregnancy rate, the secondary outcome was the number of oocytes retrieve and fertilization rate.

\section{Statistical Analysis}

Definite variables were presented as number and percentage whereas mean and standard deviation (SD) or independent samples tests were offered for numeric variables. The association between definite variables was calculated using the Chi-square test and correction was done as needed. Mean values between the two groups were compared using an independent samples test. The correlation was estimated using the superman correlation test. $\mathrm{P} \leq 0.05$ is considered statistically significant while $\mathrm{p}<0.001$ consider highly significant.

\section{Results}

The two groups of women who were treated in this study were compared to demographics characteristics involve age, BMI, infertility duration, primary or secondary infertility, and the causes of infertility, show insignificant differences for any of these demographics 
characteristics parameters $(\mathrm{P}>0.05)$ (Table 1). There were insignificant differences in any of the baseline serum hormonal concentrations between the control group and the dual trigger group $(\mathrm{P}>0.05)$ (Table 2). There was a highly significant difference in mean serum hCG hormone on day oocyte pick up between control and dual trigger group with the level being higher in the hCG control group $(\mathrm{P}<0.001)$. Despite the serum progesterone level seems to be higher in the hCG group but no significant difference between both groups $(\mathrm{P}=0.090)$. Serum $\mathrm{E}_{2}$ and serum testosterone show no significant difference in both groups $(\mathrm{P}=0.874 ; 0.999)$ respectively (Table 3 ). There was a highly significant difference in mean total oocyte between the control group and dual trigger group, $(\mathrm{P}=0.010)$; being higher in the dual trigger group, meanwhile, a mean number of fertilized oocytes was higher in a dual group than the control group, however, the difference showed borderline statistical significance $\quad \mathrm{P}=0.052$. Regarding fertilization rates between the control group and the dual group, there was no significant difference between both groups $\mathrm{P}>0.05$. (Table 4). The rate of clinical pregnancy was higher in the dual trigger group than in the control group, however, the difference did not reach statistical significance $(\mathrm{P}=0.284)$ (Table 5).

\section{Discussion}

Using GnRH-a to trigger oocyte maturation is associated with advantageous more release of FSH and LH, thereby simulating the natural menstrual cycle and hence it can replace the use of the hCG administration in protocols (Humaidan, et al. [10]; Griesinger, et al., $\left.{ }^{[11]}\right)$. Later on, "dual triggering" was proposed as being composed of combined GnRH-a and a low-dose HCG for final oocyte maturation (Shapiro, et al. ${ }^{[12]}$ ). On the day of oocyte retrieval, the mean serum hormones level reveals no significant difference in mean serum estradiol $\left(E_{2}\right)$, progesterone (it was higher), and testosterone between the control group and dual trigger group but, 
Table (1): Demographic characteristics of women according to type of trigger (dual versus hCG)

\begin{tabular}{|c|c|c|c|}
\hline Patient Characteristic & $\begin{array}{c}\text { Control (hCG trigger) } \\
n=40 \\
\end{array}$ & $\begin{array}{c}\text { Dual trigger } \\
n=40\end{array}$ & $P$-value \\
\hline \multicolumn{4}{|c|}{ Age (years) } \\
\hline Mean \pm SD & $28.18 \pm 5.88$ & $28.63 \pm 4.71$ & \multirow{2}{*}{$\begin{array}{l}0.707 \dagger \\
\mathrm{NS}\end{array}$} \\
\hline Range & $18-39$ & $19-39$ & \\
\hline \multicolumn{4}{|c|}{ BMI $\left(\mathrm{kg} / \mathrm{m}^{2}\right)$} \\
\hline Mean \pm SD & $26.11 \pm 3.40$ & $26.82 \pm 3.21$ & \multirow{2}{*}{$\begin{array}{c}0.337 \dagger \\
\mathrm{NS}\end{array}$} \\
\hline Range & $17.53-31.25$ & $22.55-34.34$ & \\
\hline \multicolumn{4}{|c|}{ Infertility duration (years) } \\
\hline Mean \pm SD & $6.70 \pm 4.40$ & $6.10 \pm 3.46$ & \multirow{2}{*}{$\begin{array}{c}0.500 \dagger \\
\text { NS }\end{array}$} \\
\hline Range & $2-18$ & $2-17$ & \\
\hline \multicolumn{4}{|c|}{ Type of infertility } \\
\hline Primary, $n(\%)$ & $31(77.5 \%)$ & $29(72.5 \%)$ & \multirow{2}{*}{$\begin{array}{c}0.606 ¥ \\
\text { NS }\end{array}$} \\
\hline Secondary, $n(\%)$ & $9(22.5 \%)$ & $11(27.5 \%)$ & \\
\hline \multicolumn{4}{|c|}{ Infertility cause } \\
\hline PCOS, $n(\%)$ & $9(22.5 \%)$ & $8(20.0 \%)$ & \multirow{4}{*}{$\begin{array}{l}0.309 ¥ \\
\text { NS }\end{array}$} \\
\hline Ovulatory, $n(\%)$ & $0(0.0 \%)$ & $1(2.5 \%)$ & \\
\hline Tubal, $n(\%)$ & $8(20.0 \%)$ & $14(35.0 \%)$ & \\
\hline Unexplained, $n(\%)$ & $23(57.5 \%)$ & $17(42.5 \%)$ & \\
\hline
\end{tabular}

$\boldsymbol{n}$ : number of cases; SD: standard deviation; BMI: body mass index; PCOS: polycystic ovary syndrome; $\uparrow$ : Independent samples test; ¥: Chi-square test; NS: not significant at $P>0.05$ 
Table (2): Baseline hormonal levels of women according to type of trigger (dual versus hCG)

\begin{tabular}{|c|c|c|c|}
\hline Baseline Hormone & $\begin{array}{c}\text { Control (hCG trigger) } \\
n=40 \\
\end{array}$ & $\begin{array}{c}\text { Dual trigger } \\
n=40\end{array}$ & P-value \\
\hline \multicolumn{4}{|c|}{ FSH mIU/ml } \\
\hline Mean \pm SD & $6.04 \pm 2.38$ & $6.81 \pm 2.51$ & \multirow{2}{*}{$\begin{array}{l}0.165 \dagger \\
\mathrm{NS}\end{array}$} \\
\hline Range & $2.2-13.9$ & $2.7-13.6$ & \\
\hline \multicolumn{4}{|c|}{ LH mIU/ml } \\
\hline Mean \pm SD & $4.98 \pm 2.63$ & $5.13 \pm 2.63$ & \multirow{2}{*}{$\begin{array}{l}0.790 \dagger \\
\mathrm{NS}\end{array}$} \\
\hline Range & $1.8-11.8$ & $1-15$ & \\
\hline \multicolumn{4}{|c|}{$\mathrm{E}_{2} \mathrm{pg} / \mathrm{ml}$} \\
\hline Mean \pm SD & $34.05 \pm 13.33$ & $36.25 \pm 16.43$ & \multirow{2}{*}{$\begin{array}{l}0.513 \dagger \\
\mathrm{NS}\end{array}$} \\
\hline Range & $4.2-62.7$ & $9-73$ & \\
\hline \multicolumn{4}{|c|}{ Prolactin ng/ml } \\
\hline Mean \pm SD & $21.90 \pm 14.05$ & $20.42 \pm 13.49$ & \multirow{2}{*}{$\begin{array}{l}0.632 \dagger \\
\mathrm{NS}\end{array}$} \\
\hline Range & $0.83-76$ & $3.1-66.7$ & \\
\hline \multicolumn{4}{|c|}{ Progesterone ng/ml } \\
\hline Mean \pm SD & $0.54 \pm 0.52$ & $3.94 \pm 15.73$ & \multirow{2}{*}{$\begin{array}{l}0.177 \dagger \\
\mathrm{NS}\end{array}$} \\
\hline Range & $0.2-3.5$ & $0.15-95$ & \\
\hline \multicolumn{4}{|c|}{ TSH mIU/ml } \\
\hline Mean \pm SD & $2.20 \pm 1.26$ & $2.28 \pm 1.08$ & \multirow{2}{*}{$\begin{array}{l}0.781 \dagger \\
\quad \mathrm{NS}\end{array}$} \\
\hline Range & $0.4-6.7$ & $0.65-6$ & \\
\hline \multicolumn{4}{|c|}{ Testosterone ng/ml } \\
\hline Mean \pm SD & $3.00 \pm 11.20$ & $0.70 \pm 0.43$ & \multirow{2}{*}{$\begin{array}{l}0.197 \dagger \\
\mathrm{NS}\end{array}$} \\
\hline Range & $0.01-63$ & $0.14-2.6$ & \\
\hline
\end{tabular}

FSH: follicle stimulating hormone; LH: luteinizing hormone; E2: estradiol; TSH: thyroid stimulating hormone; n: number of cases; SD: standard deviation; $\uparrow$ : Independent samples test; NS: not significant at $\mathrm{P}>0.0$ 
Table (3): Serum hormonal levels of women on day of pickup according to type of trigger (dual versus hCG)

\begin{tabular}{|c|c|c|c|}
\hline Serum hormone & $\begin{array}{c}\text { Control (hCG trigger) } \\
n=40\end{array}$ & $\begin{array}{c}\text { Dual trigger } \\
n=40\end{array}$ & $P$-value \\
\hline \multicolumn{4}{|c|}{$\mathbf{E}_{2}$} \\
\hline Mean \pm SD & $1027.20 \pm 483.69$ & $1047.00 \pm 625.00$ & \multirow{2}{*}{$\begin{array}{l}0.874 \dagger \\
\mathrm{NS}\end{array}$} \\
\hline Range & $266.31-2237.00$ & $70.00-2591.00$ & \\
\hline \multicolumn{4}{|c|}{ Progesterone } \\
\hline Mean \pm SD & $7.69 \pm 4.49$ & $6.00 \pm 4.34$ & \multirow{2}{*}{$\begin{array}{l}0.090 \dagger \\
\mathrm{NS}\end{array}$} \\
\hline Range & $2.20-25.50$ & $0.95-16.50$ & \\
\hline \multicolumn{4}{|c|}{ hCG } \\
\hline Mean \pm SD & $172.07 \pm 88.11$ & $82.67 \pm 44.59$ & \multirow{2}{*}{$\begin{array}{c}<0.001 \dagger \\
\mathrm{HS}\end{array}$} \\
\hline Range & $0.10-437.80$ & $8.80-209.00$ & \\
\hline \multicolumn{4}{|c|}{ Testosterone } \\
\hline Mean \pm SD & $0.74 \pm 0.36$ & $0.74 \pm 0.41$ & \multirow{2}{*}{$\begin{array}{l}0.999 \dagger \\
\mathrm{NS}\end{array}$} \\
\hline Range & $0.15-1.66$ & $0.19-172.00$ & \\
\hline
\end{tabular}

Table (4): Oocyte characteristics and fertilization rate of women according to type of trigger (dual versus hCG)

\begin{tabular}{|c|c|c|c|}
\hline Oocytes Characteristic & $\begin{array}{c}\text { Control (hCG trigger) } \\
n=40\end{array}$ & $\begin{array}{c}\text { Dual trigger } \\
n=40\end{array}$ & P-value \\
\hline \multicolumn{4}{|c|}{ Total oocyte number } \\
\hline Mean \pm SD & $9.68 \pm 5.33$ & $12.82 \pm 5.39$ & \multirow{2}{*}{$\begin{array}{c}0.010 \dagger \\
\text { HS }\end{array}$} \\
\hline Range & $2-26$ & $3-23$ & \\
\hline \multicolumn{4}{|c|}{ Fertilized oocyte } \\
\hline Mean \pm SD & $4.78 \pm 3.10$ & $6.10 \pm 2.91$ & \multirow{2}{*}{$\begin{array}{c}0.052 \dagger \\
\mathrm{NS}\end{array}$} \\
\hline Range & $1-17$ & $1-13$ & \\
\hline \multicolumn{4}{|c|}{ Fertilization rate } \\
\hline Mean \pm SD & $70.92 \pm 22.71$ & $75.40 \pm 18.97$ & \multirow{2}{*}{$\begin{array}{c}0.341 \dagger \\
\mathrm{NS}\end{array}$} \\
\hline Range & $23.07-100$ & $33.33-100$ & \\
\hline
\end{tabular}


Table (5): Clinical pregnancy rate of women according to type of trigger (dual versus hCG)

\begin{tabular}{|c|c|c|c|c|c|}
\hline \multirow{2}{*}{ Clinical pregnancy } & \multicolumn{2}{|c|}{ Control (hCG trigger) } & \multicolumn{2}{c|}{ Dual trigger } & \multirow{2}{*}{$\boldsymbol{P}$-value } \\
\cline { 2 - 5 } & $\boldsymbol{n}$ & $\%$ & $\boldsymbol{n}$ & $\%$ & \\
\hline Positive, $\boldsymbol{n}(\%)$ & 7 & 17.5 & 11 & 27.5 & $0.284 ¥$ \\
Negative, $\boldsymbol{n}(\%)$ & 33 & 82.5 & 29 & 72.5 & NS \\
\hline
\end{tabular}

there was a highly significant difference in mean serum hCG between both group with higher level toward hCG group. By current study findings (Griffin, et al., ${ }^{[13]}$ ) have been shown that the level of estradiol $\left(\mathrm{E}_{2}\right)$ was comparable between dual and hCG triggering groups. The current study observation of higher total oocyte number in association with the use of dual triggering instead of hCG triggering alone is the as that of (Lin, et al. ${ }^{[14]}$; Haas, et al. ${ }^{[15]}$ ) who demonstrated a significantly greater number of total oocytes number in the dual triggering group than in $\mathrm{hCG}$ triggering alone. The result of the current study shows no significant difference in fertilization rates between the control group and the dual trigger group $(\mathrm{P}>0.05)$. (Griffin, et al., ${ }^{[13]}$ ), has demonstrated that fertilization rate was higher in the dual triggering group than in the $\mathrm{hCG}$ group, but with statistical insignificance, just in line with current study observation. On the other hand, (Lin, et al. ${ }^{[16]}$ ) have reported a significantly higher fertilization rate in association with dual triggering in comparison with hCG triggering alone. In the present study, the clinical pregnancy rate was higher in the group of women receiving dual triggering in comparison with women receiving $\mathrm{hCG}$ triggering only, but the difference was statistically insignificant. In support for current study findings, (Lin, et al. ${ }^{[16]}$ ) have reported higher clinical pregnancy and live birth rates in association with dual triggering than the conventional hCG triggering, but the difference was statistically significant, probably because of the higher sample 
size 427 versus only 80 cases in the current study. In addition, other previous studies have shown that dual triggering is associated with significantly higher clinical pregnancy rate and live birth rate than hCG triggering alone (Lin, et al., ${ }^{[14]}$; Schachter, et al. $\left.{ }^{[17]}\right)$, supporting partly the results of the current study. The present study derives that the dual trigger using for final oocytes maturation in antagonist ICSI cycles increase the number of oocytes retrieved with highly statistically significant and more pregnancy rate in dual trigger group although it does not reach statistically significant because the present study had some limitations including relatively small sample size, a large sample prospective randomized control study needs to confirm this finding.

\section{Conclusions}

This study suggests that dual trigging use of $0.2 \mathrm{mg}$ of $\mathrm{GnRH}$ agonist (triptorelin) plus recombinant hCG $250 \mu \mathrm{g}$ compared to hCG alone for final oocyte maturation in fresh autologous GnRH-antagonist ICSI cycles, could be associated with improved outcome. An increase in the total number of retrieved oocytes, higher fertilized oocytes, and clinical pregnancy rates, appears to be a promising option for patients suffering from a lower number of oocytes retrieved in the previous ICSI cycle. Large prospective studies with large samples are required to confirm the role and the beneficial effect of dual triggers in implantation, clinical pregnancy, mischarge, and live birth rates.

\section{Acknowledgment}

We would like to acknowledge the High Institution of Infertility Diagnosis and Assisted Reproductive Technologies, Al Nahrain University, Baghdad, Iraq.

\section{Funding}

This work received no funding.

\section{Author Contribution}

Abed, WM performed the study, examined and reviewed results, and manuscript writing with the help and supervision of Selman, MO. 


\section{Conflict of Interest}

The author declares no conflict of interest.

\section{Ethical Clearance}

This study protocol was approved by the local Ethical Committee of a high institute for diagnosis infertility and the Assisted Reproductive Technique. Written informed consent was obtained from each individual who participated in this study.

\section{References}

[1]Allegra A, Marino A, Volpes A, Coffaro F, Scaglione P, Gullo S, La Marca A. A randomized controlled trial investigating the use of a predictive nomogram for the selection of the FSH starting dose in IVF/ICSI cycles. Reprod Biomed Online. 2017;34(4):429-438. [Online Article Link]

[2]Behery MA, Hasan EA, Ali EA. Comparative study between agonist and antagonist protocols in PCOS patients undergoing ICSI: a crosssectional study. Middle East Fertil Soc J. 2020;24(2). [Online Article Link]

[3] Griffin D, Feinn R, Engmann L, Nulsen J, Budinetz $T$, Benadiva $C$. Dual trigger with gonadotropinreleasing hormone agonist and standard-dose human chorionic gonadotropin to improve oocyte maturity rates. Fertil Steril. 2014;102(2):405-9. [Online Article Link]

[4] Lawrenz B, Garrido N, Samir S, Ruiz F, Melado L, Fatemi H. Individual luteolysis pattern after GnRH- agonist trigger for final oocyte maturatin. PLoS One. 2017;12(5):e0176600. [Online Article Link]

[5]El Tokhy O, Kopeika J, Ell-Joukhy J. An update on the prevention of ovarian hyper stimulation syndrome. Women's Health, 2016;12(5):496-503. [Online Article Link]

[6] Eftekhar M, Naghshine E, Neghab N, Hosseinisadat R. A comparison of dual triggering (by administration of $\mathrm{GnRH}$ agonist plus HCG) versus HCG alone in poor ovarian responder in ART outcomes. Middle East Fertility Society Journal. 2018;23(4):350-353. [Online Article Link]

[7] Rosini R, Campisi E, De Chiara M, Tettelin H, Rinaudo D, Toniolo C. Genomic analysis reveals the molecular basis for capsule loss in the group B streptococcus population, PLoS One. 2015;10:e0125985.

[Online Article Link]

[8] Vuong LN, Pham TD, Ho VNA, Ho TM, Humaidan $\mathrm{P}$, Andersen CY. Determinants of the hCG concentration in the early luteal phase after final maturation of follicles with 
bolus trigger of recombinant hCG. Front. Endocrino. 2020;11:137,1-7. [Online Article Link]

[9] Mohammed A, Woad KJ, Mann GE, Craigon J, Rain-fennig N, Robinson R. Evaluation of progesterone supplementation for luteal phase support in fresh in vitro fertilization cycles. Fertility and Sterility. 2019;112(3):491-502.e3. [Online Article Link]

[10] Humaidan P, Kol S, Papankolaou, EG. GnRH agonist for triggering of final oocyte maturation: Time for a change of practice? Hum Reprod Update. 2011;17:510-524. [Online Article Link]

[11] Griesinger G, Diedrich K, Devroey $\mathrm{P}$, Kolibianakis EM. 'GnRH agonist for triggering final oocyte maturation in the GnRH antagonist ovarian hyperstimulation protocol: a systematic review and meta-analysis', Hum Reprod Update. 2005;12(2):15968. [Online Article Link]

[12] Shapiro BS, Daneshmand ST, Garner FC, Aguirre M, Thomas S. Gonadotropin-releasing hormone agonist combined with a reduced dose of human chorionic gonadotropin for final oocyte maturation in fresh autologous cycles of in vitro fertilization. Fertil. Steril. 2008;90(1)231-233. [Online Article Link]
[13] Griffin D, Engmann L, Budinetz T, Kummer N, Nulsen J, Benadiva C. Dual trigger with gonadotropin releasing hormone agonist (GnRHa) and human chorionic gonadotropin (hCG) for the treatment of 'immature oocyte syndrome'(IOS). Fertil Steril. 2012;98(3):S156. [Online Article Link]

[14] Lin MH, Wu FS, Lee RK, Li S, Lin S, Hwu Y. Dual trigger with combination of gonadotropin-releasing hormone agonist and human chorionic gonadotropin significantly improves the live-birth rate for normal responders in GnRH-antagonist cycles, Fertil. Steril. 2013;100(5):1296-1302. [Online Article Link]

[15] Haas J, Ophir L, Barzilay E, Machtinger R, Yung Y, Orvieto R, Hourvitz A. Standard human chorionic gonadotropin versus double trigger for final oocyte maturation results in different granulosa cells gene expressions: a pilot study, Fertil Steril, 2016;106(3):653-659.e1. [Online Article Link]

[16] Lin MH, Wu FS, Hwu YM, Lee RK, Li RS, Li SH. Dual trigger with gonadotropin releasing hormone agonist and human chorionic gonadotropin significantly improves live birth rate for women with diminished ovarian reserve, Reproductive biology and 
endocrinology, 2019;17(1):7. [Online Article Link]

[17] Schachter M, Friedler S, Ron-El R, Zimmerman AL, Strassburger, D Bern O. Can pregnancy rate be improved in gonadotropin-releasing hormone (GnRH) antagonist cycles by administering GnRH agonist before oocyte retrieval? A prospective, randomized study, Fertil Steril, 2008;90(4):1087-1093. [Online Article Link]

\section{Authors Biographies}

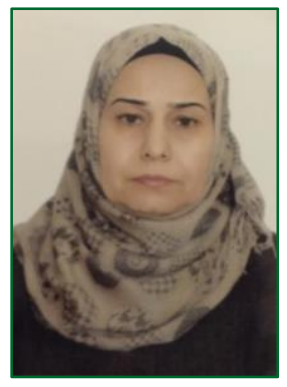

\section{Dr. Wafaa Mohammed Abed}

She received $\mathrm{MBChB}$ of Medicine and General Surgery, University of Mosul, College of Medicine in 1991, the Higher Diploma in obstetrics and gynecology, Al Mustansiriya University, College of Medicine in 1998. She received the higher diploma equivalent to a Master in Assisted Reproductive Technologies, Al Nahrain University, Higher Institute for Infertility Diagnosis and Assisted Reproductive Technologies in 2013. Currently, she is a Ph.D. student in clinical applied reproductive physiology, Al Nahrain University, Higher Institute for Infertility Diagnosis and Assisted Reproductive Technologies from 20172020. She was the head of the obstetrics and gynecology department, Al Kut gynecology and children's hospital from 2002-2011. She served as the director of the infertility unit, Al Kut hospital for women and children from 2014-2017. She is actively attending seminars, training courses, lectures, and workshops for obstetrics and gynecology associations and infertility associations inside and outside Iraq. She is a member of the Iraqi Fertility Society.

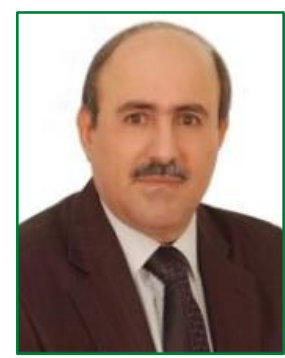

international.

\section{Dr. Mohammed Oda Selman}

$\mathrm{He}$ is a professor of Applied Embryology in the High Institute for Infertility Diagnosis and ART, Al-Nahrain University. He has more than 70 published articles both local and $\mathrm{He}$ supervised many M.Sc. and Ph.D. students.

\section{How to cite:}

Abed WM; Selman MO. Outcome of GnRH antagonist ICSI cycles triggered by GnRH agonist plus Recombinant hCG versus triggered with Recombinant hCG alone in fresh autologous ICSI cycle; Iraqi Journal of Embryos and Infertility Researches (IJEIR), (2020); 10(1): 119-131. Doi: http://doi.org/10.28969/IJEIR.v10.i1.r8

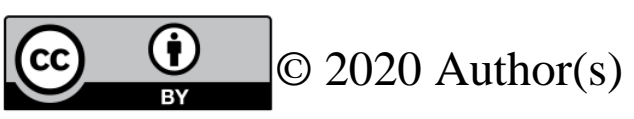

This article is licensed under a Creative Commons Attribution 4.0 International License, which permits use, sharing, adaptation, distribution and reproduction in any medium or format, as long as you give appropriate credit to the original author(s) and the source, provide a link to the Creative Commons license, and indicate if changes were made. http://creativecommons.org/licenses/by/4.0/. 